gone. The fact that $44 \%$ of patients when asked postoperatively did not know the basic facts about their operation is an indictment both of surgeryand there is little reason to suppose that the result would have been much different elsewhere-and of the level of awareness of health and disease in the general population. It also happens occasionally that patients arrive at hospital for admission without knowing why they have been sent for; this cannot always be explained by the length of time they have been on the waiting list.

It is surprising perhaps that as one of the authors of this study is a nurse no mention is made of the important role of the ward nurse in preoperative discussion and explanation, reference being made only to the efforts of the consultant, senior house officer, and house officer. It is my impression that on our unit here at Oxford the nurses spend as much, if not more, time as the medical staff in explaining the basic surgical details. If we too fail as many as $44 \%$ of our patients this may be yet another consequence of the need to shorten outpatient consultation times and the preoperative assessment period in the ward which have been forced on us recently in the name of efficiency.

One of the criticisms which can be levelled at Project 2000 as a model for the future of nursing in Britain is that there is very little comment on the necessity for close cooperation between nurse and doctor working as a team to provide the best form of care for the patient, and this is never more important than in surgical specialties. It is a pity if similar omissions occur in medical articles for only by further developments in the concept of the surgical team, which includes specialist theatre and ward nursing staff, will we be able to resolve the sort of problem highlighted in this paper.

\section{Malcolm Gough}

John Radcliffe Hospital,

Oxford OX3 9DU

\section{Viral infection, human papillomavirus DNA, and cervical neoplasia}

SIR,-Dr W P Soutter correctly draws our attention to recent reports in which a high prevalence of human papillomavirus type 16 DNA is found in biopsy specimens from apparently normal cervixes (12 March, $\mathrm{p} 789$ ). He concludes that the relation between human papillomavirus 16 infection and cervical malignancy must, therefore, be association rather than causation. This is only one explanation of these data. Another more worrying explanation might be that there is about to be a dramatic increase in the prevalence of cervical intraepithelial neoplasia (some suggest that this has happened already), and that there will be a major increase in the incidence of invasive cancer; this has certainly been predicted. ${ }^{1} \mathrm{~A}$ middle view is more likely. The high prevalence of human papillomavirus 16 DNA sequences, often integrated into the host cell genome in cases of invasive cancer, certainly suggests a strong association between these conditions. ${ }^{2}$

Consider the analogy of hepatitis B virus. Many people world wide are exposed to the virus. Many show no clinical illness, some have a short severe illness, many are unwitting carriers of the infection, but a minority go on to develop cancer of the liver. ${ }^{3}$ The high prevalence of evidence of infection with hepatitis B virus in apparently normal subjects who do not go on to develop cancer does not prove that the virus does not cause the cancer, simply that certain other conditions need to be fulfilled for this to occur. In the case of human papillomavirus 16 and cervical cancer it is important to direct our research towards the identification of possible cofactors which may be necessary for the virus to cause malignant transformation of cervical tissue.

Patrick Walker JOHN GILES

PaUl GRIFFITHS

Royal Free Hospital

London NW3 2QG

Beral V. Predictions of cervical cancer incidence and mortality in England and Wales. Lancet 1986; ; 495 .

2 Meanwell CA, Cox MF, Blackledge G, Maitland NJ. HPV 16 DNA in normal and malignant cervical epithelium. Implications for the aetiology and behaviour of cervical neoplasia. Lancet 1987; i: $703-7$.

3 Hsu H-Y, Chang M-H, Chen D-S, Lee C-Y, Sung J-L. Baseline seroepidemiology of hepatitis $B$ virus infection in children in Taipei, 1984. F Med Virol 1986;18:301-7.

\section{Effect of wheat bran on weight of stool}

SIR, - For a meta analysis to be valid the review of published work must be comprehensive. Dr Stefan Müller-Lissner's meta analysis (27 February, p 615) is far from comprehensive. It also fails to take into account the great variability of bran products and the heterogeneity of constipation.

A more complete review of the effects of bran on the stools of normal subjects has been published. It gives details of 16 further studies over and above the nine reviewed by Dr Müller-Lissner. Some of these show that the effect of bran varies with its particle size and that cooking reduces the effect.

Dr Müller-Lissner bases his conclusion that bran is less effective in constipated than in normal subjects on two studies of 16 patients. I submit that more data are necessary. Our own experience in 20 subjects was that slow transit constipation was corrected in $85 \%$ of cases if a sufficient dose of wheat fibre was given. ${ }^{2}$

Nevertheless, bran cannot be expected to help everyone with constipation. Straining and difficulty in expelling stool are sometimes due to failure of relaxation of the anal sphincter rather than to small, hard stools. ${ }^{3.6}$ Patients may also strain to pass normal stools if they have the irritable bowel syndrome, rectal prolapse, or solitary rectal ulcer. It is illogical to expect such patients to be helped by bran or any other bulking agent Furthermore, bulking agents are also liable to fail if rectal sensation is impaired, as it is in some patients with longstanding severe constipation.

Department of Medicine,

K W HEATON

Bristol Royal Infirmary,

Bristol BS2 8HW

Cummings $\mathrm{JH}$. The effect of dietary fiber on fecal weight and composition. In: Spiller GA, ed. CRC handbook of dietary fib in human nutrition. Boca Raton: CRC Press, 1986:211-80.

2 Marcus SN, Heaton KW. Effects of a new, concentrated whe fibre preparation on intestinal transit, deoxycholic acid metabolism and the composition of bile. Gut 1986;27:893-900. Preston DM, Lennard-Jones JE. Anismus in chronic constipation. Dig Dis Sci 1985;30:413-8.

4 Turnbull GK, Lennard-Jones JE, Bartram CI. Failure of recta expulsion as a cause of constipation: why fibre and laxatives sometimes fail. Lancet 1986; i:767-9.

5 Read NW, Timms JM, Barfield LJ, Donnelly TC, Bannister JJ. Impairment of defecation in young women with sever constipation. Gastroenterology 1986;90:53-60.

6 Shouler P, Keighley MRB. Changes in colorectal function in severe idiopathic chronic constipation. Gastroenterology 1986 90:414-20

AUTHOR'S REPLY - Dr Heaton claims that my recently published meta analysis was not comprehensive. I am also aware of further studies with bran products but, as I mentioned, I did restric the analysis to papers reporting quantitative dat on stool weight or transit time, or both. The statement that the meta analysis may not be valid because of non-comprehensiveness implies that specific data leading to different conclusions had been disregarded. I do not think this is true.

Dr Heaton claims that I based my conclusions on the data from only 16 patients. This is not true. Individual data on stool weight could be extracted for only 16 patients but the conclusions are based on the findings in 46 patients-all the quantitative data that, to my knowledge, have ever been published. Also Dr Heaton is obviously not aware of further data from patients.

I do not agree that bran cannot be efficacious in patients with anismus or internal mucosal prolapse. The opposite is true. Since impairment of defecation becomes particularly relevant when stools are small, and hence on straining, ${ }^{12}$ bulking of stools is essential. The data extracted from the papers could not be broken up into various pathophysiological entities simply because these had not been determined or at least not been reported. ${ }^{3}$

Finally, Dr Heaton claims that in his own study slow transit constipation had been "corrected" in $85 \%$ of $^{\text {cases. }}{ }^{3}$ In fact, his patients had similar transit times when treated with bran as the controls from other studies without bran. Dr Heaton's patients also had slower transit than controls whether treated with bran or not.

\section{STEFAN A MÜLLER-LISSNER}

Department of Gastroenterology,

Chirurgische Klinik Innenstadt,

D-8000 München 2

German Federal Republic

Bannister JJ, Davison P, Timms JM, Gibbons C, Read NW Effect of stool size and consistency on defecation. Gut 1987;28: 1246-50.

Read NW, Timms JM, Barfield LJ, Donnelly TC, Bannister JJ Impairment of defecation in young women with severe constipation. Gastroenterology 1986;90:53-60.

3 Marcus SN, Heaton KW. Effects of a new, concentrated wheat fibre preparation on intestinal transit, deoxycholic acid metabolism and the composition of bile. Gut 1986;27:893-900.

SIR,-Dr Stefan Müller-Lissner's meta analysis on the effects of wheat bran (27 February, p 615) has confirmed my belief that increased dietary fibre is not necessarily an effective treatment for constipation despite the evidence cited from epidemiological studies and studies of healthy subjects.

Constipation is a subject of great importance to geriatricians and others concerned in the care of the elderly as most immobile patients suffer from it, probably owing to loss of the colonic mass movements that accompany normal physical activity. ${ }^{1}$ Many also suffer faecal impaction. An association has been shown in the elderly between high dietary fibre intake and radiological evidence of colonic faecal loading. ${ }^{2}$

Geriatric patients typically suffer from slow transit constipation. ${ }^{3}$ Defecatory abnormalities similar to those described in younger patients with severe constipation ${ }^{4}$ and abnormal colonic motility are likely to contribute towards this. In contrast with younger patients, who typically have hard stools that are difficult to pass, ${ }^{5}$ the stool consistency of constipated geriatric patients is often soft or even liquid. I found that 24 of the 63 constipated geriatric patients I recently studied had soft or liquid stool (unpublished results), and this may be one of the reasons why constipation is often complicated by faecal incontinence in geriatric patients.

When the mechanism causing constipation is better understood it may be possible to identify the patients who would benefit from increased dietary fibre. In the interim I would suggest that bran should not be given to elderly patients who are constipated with soft stools, suffer from faecal impaction, or have a history suggestive of defe- 